\title{
BMJ Open Norwegian trends in numbers of lower extremity revascularisations and amputations including regional trends in endovascular treatments for peripheral arterial disease: a retrospective cross-sectional registry study from 2001 to 2014
}

\author{
Kjersti Wendt, ${ }^{1}$ Ronny Kristiansen, ${ }^{2}$ Kirsten Krohg-Sørensen, ${ }^{3,4}$ \\ Fredrik Alexander Gregersen, ${ }^{5}$ Erik Fosse ${ }^{1,4}$
}

To cite: Wendt K, Kristiansen $\mathrm{R}$, Krohg-Sørensen K, et al. Norwegian trends in numbers of lower extremity revascularisations and amputations including regional trends in endovascular treatments for peripheral arterial disease: a retrospective cross-sectional registry study from 2001 to 2014. BMJ Open 2017;7:e016210. doi:10.1136/ bmjopen-2017-016210

\section{- Prepublication history and} additional material for this paper are available online. To view these files, please visit the journal online (http://dx.doi. org/10.1136/bmjopen-2017016210).

Received 31 January 2017 Revised 8 August 2017 Accepted 9 August 2017

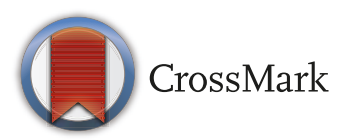

For numbered affiliations see end of article.

Correspondence to

Kjersti Wendt;

wendtkjersti@gmail.com

\section{ABSTRACT}

Objective The numbers of lower extremity revascularisations and amputations are insufficiently reported in Norway. To support future policy decisions regarding the provision of vascular treatment, knowledge of such trends is important.

Methods This retrospective cross-sectional study from 2001 to 2014 used data from the Norwegian Patient Registry. The revascularisation treatments were categorised in multilevel, aortoiliac, femoral to popliteal and popliteal to foot levels and sorted as open, endovascular and hybrid. The sessions in amputations were divided in major (thigh and below knee) and minor (ankle, foot or digit). Incidence rates were assessed per 100000 for patients in the age group $\geq 60$ years. The diabetic prevalence was calculated and the endovascular numbers at the South-Eastern, Western, Central and Northern Norway Regional Health Authority were compared.

Results The overall revascularisation rates increased from 308.7 to $366.8(p=0.02)$. Open revascularisations decreased from 158.9 to $98.7(p<0.01)$ while endovascular revascularisations increased from 142.2 to $243.4(p<0.01)$. Hybrid revascularisations increased from 7.4 to $24.8(p<0.01)$. Major amputation rates decreased from 87.8 to $48.7(p<0.01)$ while minor amputations increased from 12.3 to $19.6(p=0.01)$. The diabetic percentages increased from 12.2 to $22.3(p<0.01)$ in revascularisations, from 26.5 to $30.8(p=0.02)$ in major amputations and from 43.0 to $49.3(p=0.13)$ in minor. ( $p$ values refer to average annual changes.) The regional trends in endovascular treatments varied within and between the vascular groups.

Conclusion From 2001 to 2014, the revascularisation rates increased due to the rise in endovascular procedures. Open revascularisations and major amputation rates decreased, minor increased. The regional variances in endovascular treatments indicate that the availability of this technology differed between the health regions of
Strengths and limitations of this study

- This study is the first to demonstrate Norwegian trends in the numbers of open and endovascular treatments for peripheral arterial disease including lower extremity amputations, the diabetic prevalence in these treatments and the regional variances in use of endovascular technology.

- The study provides valuable knowledge for future provision of vascular treatment.

- Results are subject to potential errors in records, coding and analysis.

- The data were anonymous and did not include outcome measures.

- The study was not designed to establish causal relations.

Norway. The increase in patients with diabetes requires continued awareness of diabetes and its complications.

\section{INTRODUCTION}

Endovascular procedures are now more commonly performed than open surgery in many Western countries in the invasive treatment of lower peripheral arterial disease. This has led to an increase in revascularisation rates during the past decades and more patients are treated. ${ }^{12}$ The only randomised controlled trial comparing the effectiveness of endovascular intervention with open surgery so far, reported similar short-term outcomes between the two treatment strategies, ${ }^{3}$ and in recent guidelines an 'endovascular-first-strategy' is advocated for almost all types of lesions. Although at a decreasing 
rate, some complex lesions are still ideally treated by surgical approach. ${ }^{4}$

On a global level, peripheral arterial disease is one of the most prevalent, morbid and mortal diseases and affected more than 202 million individuals in 2010. The disease is now reported coprevalent among men and women in high-income countries and possibly more prevalent in women than men in low- and middle-income countries. Peripheral arterial disease is relatively uncommon in people younger than 40 years but affects 1 in 10 people aged 70 years and 1 in 6 people older than 80 years. The prevalence of the disease increased by $23.5 \%$ between 2000 and $2010 .{ }^{56}$

Smoking and diabetes are identified as the most important risk factors associated with the development of the disease. ${ }^{57}$ Smoking relates to atherosclerosis of proximal segments, diabetes to that of the distal segments. ${ }^{8}$ Peripheral arterial disease is more severe and progresses more rapidly in people with diabetes than those without. These patients are also at higher risk for lower extremity amputations and reamputations. ${ }^{9}{ }^{10}$ In patients with diabetes who are smokers, there is an additive risk. ${ }^{11}$ Smoking cessation is associated with a decline in the incidence of peripheral arterial disease. ${ }^{12}$

Recent studies have demonstrated a decrease in major amputations rates and a slight increase in minor amputations. ${ }^{21314}$ An association between the increased application of endovascular technology and the reduced major amputation rates in patients with peripheral arterial disease has been suggested. ${ }^{15}$ Advances in medical therapy, decreased smoking prevalence and widespread improvements in peripheral arterial disease screening programme are other likely explanations for the reduction in major amputation rates. ${ }^{16}$

Norwegian numbers of lower extremity revascularisations and amputations have been insufficiently reported. To support future policy decisions regarding the provision of vascular treatment in the country, knowledge about these trends is important. The objective of this study was to investigate the Norwegian changes in numbers of open and endovascular revascularisations and lower extremity amputations and assess the diabetic prevalence in these treatments from 2001 to 2014. With regards to the political goal of equitable healthcare in the country, we also investigated and compared regional trends in endovascular treatments.

\section{MATERIAL AND METHODS}

The material was based on retrospective analysis of anonymous treatment sessions extracted from the Norwegian Patient Registry (NPR). ${ }^{17}$ This is an independent, administrative registry of all patient treatment sessions (including also outpatients) in the public healthcare of Norway. The registry was established in 1997 and is owned by the Norwegian Ministry of Health and Care Services. The Norwegian Directorate of Health granted permission to use the anonymous data.
The unit of analysis was the treatment sessions including procedure $^{18}$ and diagnosis codes ${ }^{19}$ as listed in online supplementary appendix 1A, 1B, 1C and 1D. The inclusion of all diagnosis codes from the Norwegian version of International Classification of Diseases (ICD) I70-I7 $79^{19}$ was considered the best alternative for all groups to avoid inaccuracies and possible errors in the diagnostic coding. The listed vascular procedure codes are closely connected to peripheral arterial disease. This is not as evident for the procedure codes in the amputation groups. Consequently, amputations caused by any arterial disease from ICD I70-I79 ${ }^{19}$ were included in the study. However, it is reasonable to assume that the vast majority of these lower extremity amputations were actually caused by peripheral arterial disease. ${ }^{20}{ }^{21}$ Amputations caused by other conditions such as trauma, venous and lymphatic disorders and malignancies were excluded. All treatment sessions were analysed in combination with these variables: the patient's age, sex, treatment site (hospital or health trust) and home county. As the majority of treatments $(86.8 \%)$ were on patients aged $\geq 60$ years this age group was used for calculation of incidence rates per 100000 . For transparency, the numbers of treatment sessions in the age groups $<60$ and $\geq 60$ years were compared (see online supplementary appendix 2A, 2B, 2C, 2D and 2E). Numbers for the per capita calculations and developments in national smoking habits were obtained from Statistics Norway. ${ }^{22}$

The treatments in the revascularisation group were categorised in four groups: multilevel (across the aortoiliac and infrainguinal levels), on the aortoiliac level, on the femoral to popliteal level and on the popliteal to foot level and sorted into open, endovascular and hybrid treatments. Hybrid treatments were defined as a combination of open and endovascular procedures. We identified a small number of endoscopic aortoiliac and infrainguinal treatment sessions. These were excluded from further analyses. The treatments in the lower extremity amputation group were divided in major amputations (thigh and below knee), major amputation revisions, minor amputations (ankle, foot or digit) and minor amputation revisions. National incidence rates are presented in table $1 \mathrm{~A}$ and figures $1-5$ and the numbers (\%) of treatments in individuals with diabetes in table 1B. The hybrid treatments were added to the endovascular treatments in the analysis of regional variances shown in tables 2, 3, 4 and 5. Two of the authors cross-checked the extraction of data from the NPR and performed the analysis independently to increase the reliability of the results.

Since 2002, the Norwegian government has been responsible for the specialist healthcare service in the country. The hospitals are organised into health trusts, which again are grouped into regional health authorities. During the study period, some hospitals reported directly to the NPR while others reported to their health trust from which the number of treatments were forwarded collectively. Centralising efforts from the health authorities reduced the number of health trusts from 47 in 2001 to 26 in 2014. To avoid overly detailed information about 


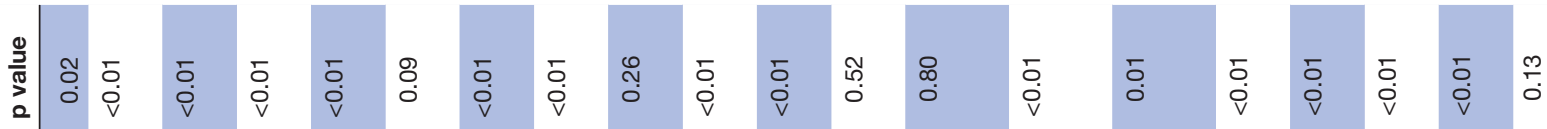

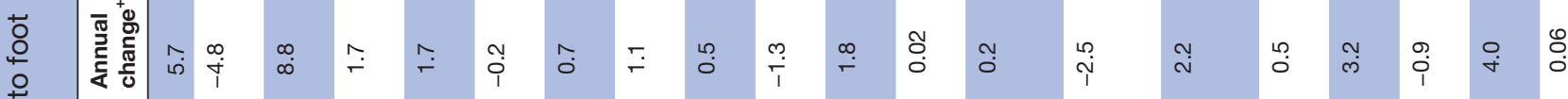

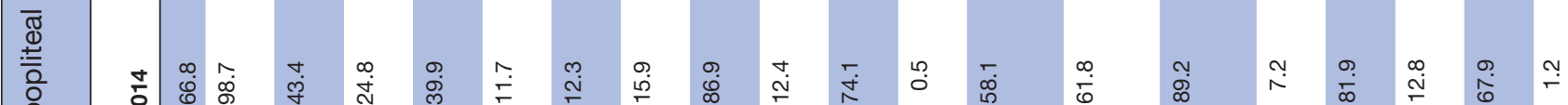

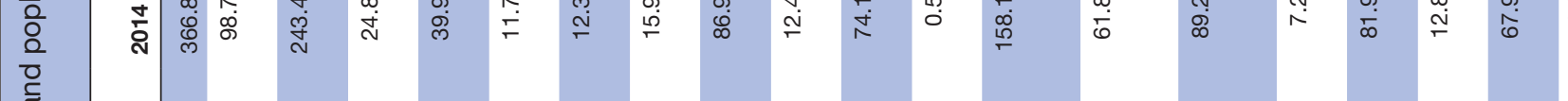

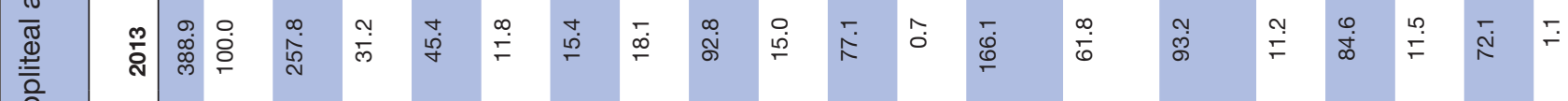

웅

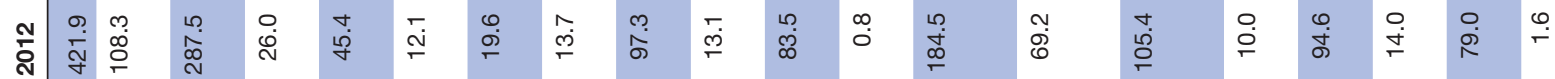

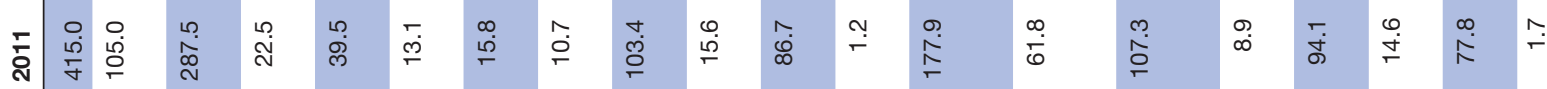

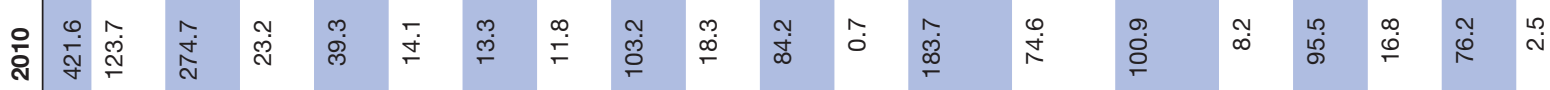

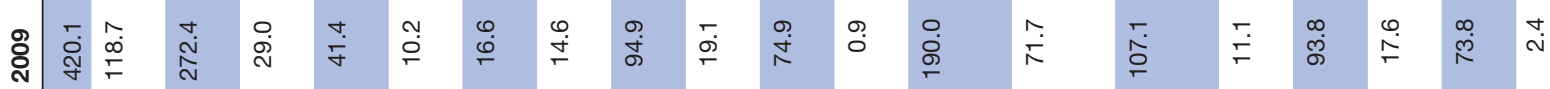

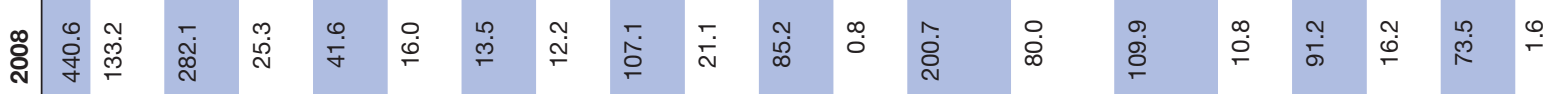

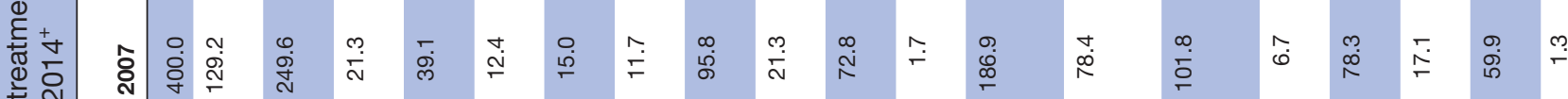

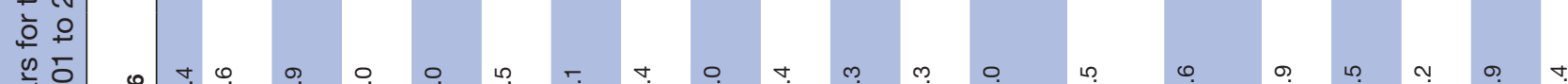

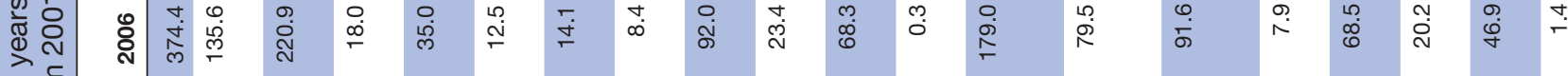

○ิ

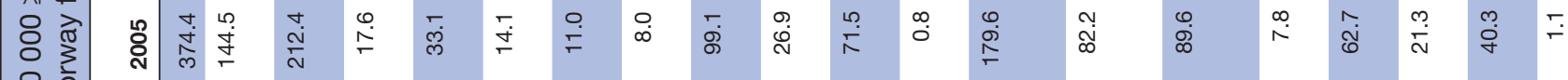

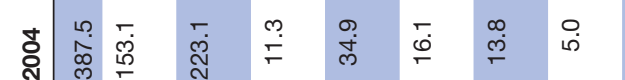

幽 $\frac{0}{\frac{\pi}{\pi}}$

ปิ

它

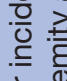

흔

है

$\frac{1}{\partial} \frac{\partial}{\partial}$

.

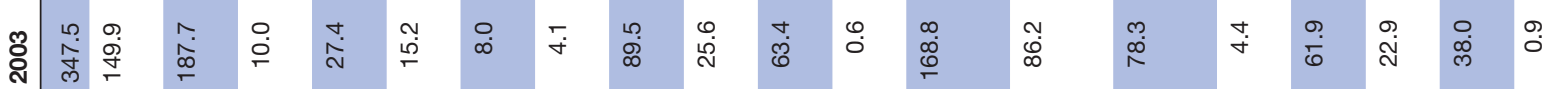

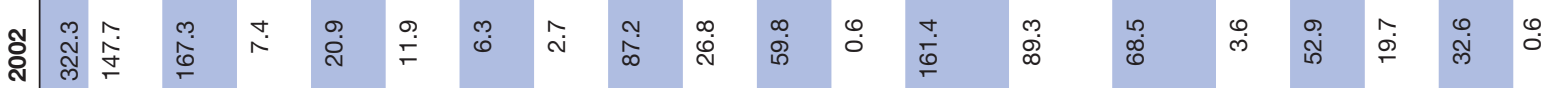

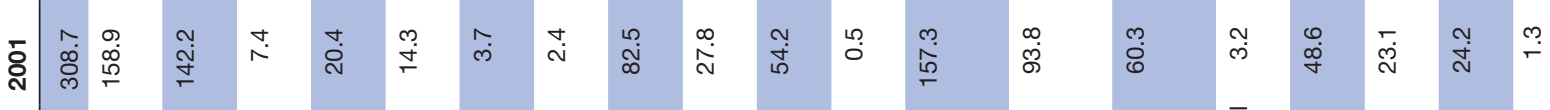

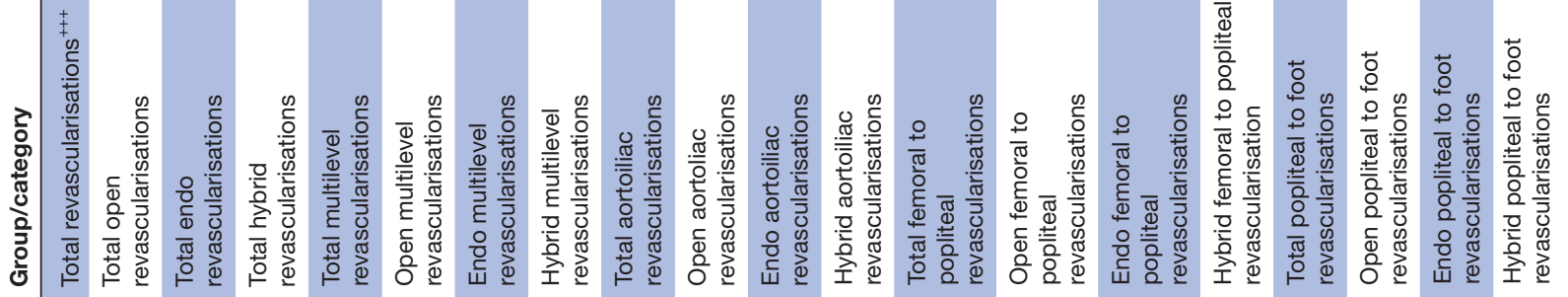


trends in hospitals and health trusts that merged with others during the period, the lowest level of treatment site used in the analyses was the Norwegian Regional Health Authorities (NRHAs). In 2007, the number of authorities was reduced from five to four as the South and the Eastern NRHA merged. For practical reasons, the current organisational model with the South-Eastern, Western, Central and Northern NRHA was used.

\section{Statistical analyses}

The statistical analyses were performed with Stata V.14.0 (Stata Corp). We used linear regression with analytical weights to calculate average annual changes in rates and percentages, and the two-sample test of proportions. The significance level was set at $\leq 0.05$.

\section{RESULTS}

From 2001 to 2014, the population of Norway increased from 4.5 to 5.1 million. The proportion aged $\geq 60$ years increased from $19.3 \%$ to $21.5 \%$. The South-Eastern NRHA was the largest authority with responsibility for more than half of the population, 2.8 million in 2014. The corresponding population was 1.1 in the Western, 0.7 in the Central and 0.5 in the Northern NRHA. ${ }^{22}$

A total of 55028 treatment sessions were categorised in the four revascularisation groups while 13074 treatment sessions were categorised in the four lower extremity amputation groups.

6060 of the vascular treatment sessions below the infrainguinal level included procedure codes from both the femoral to popliteal and the popliteal to foot level and were categorized in both groups. Some of the vascular sessions also included procedure codes from the amputation group. These combined treatments were identified in $1370(2.5 \%)$ of the vascular sessions.

\section{Multilevel revascularisations \\ Total numbers}

Treatment sessions of 5738 were identified as multilevel revascularisations. In these, $4922(85.8 \%)$ of the patients were aged $\geq 60$ years and $3472(60.5 \%)$ were men. Multilevel treatments of $2082(36.3 \%)$ contained only open procedure codes while 2005 (34.9\%) contained only endovascular procedure codes. Treatments of 1651 (28.8\%) contained both and were categorised as hybrid multilevel treatments (see online supplementary appendix 2A).

\section{Incidence rates}

The annual incidence rates of multilevel revascularisations increased from 20.4 in 2001 to 39.9 in 2014 per 100 000 for the age group $\geq 60$ years. Applying linear regression with year (time) as the independent variable, the average annual increase in these incidence rates per 100 000 was $1.7(\mathrm{p}<0.01)$. The open multilevel revascularisations decreased from 14.3 to 11.7 (annual change -0.2; $\mathrm{p}=0.09$ ), while the endovascular increased from 3.7 to 12.3 (annual change $0.7 ; \mathrm{p}<0.01$ ). The hybrid treatments 


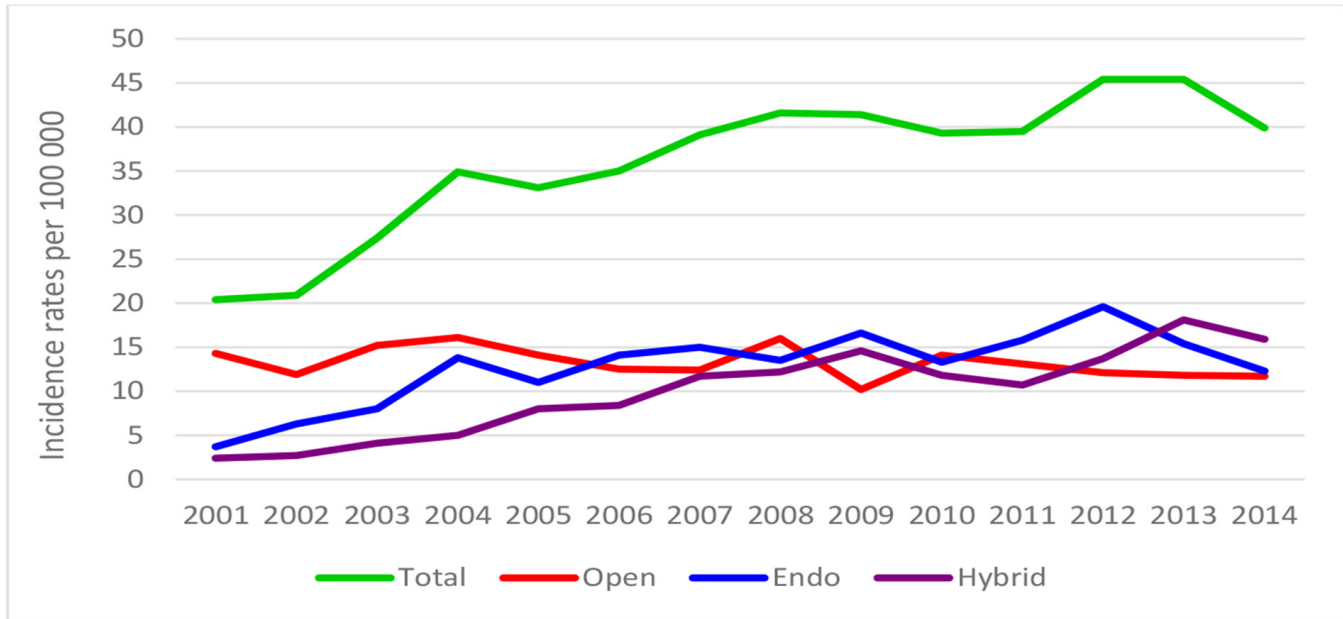

Figure 1 Trends in multilevel revascularisations (treatment sessions) in age group $\geq 60$ years.

increased from 2.4 to 15.9 (annual change 1.1; $<<0.01$ ). (table 1A)

Developments of treatments in individuals with diabetes

The treatments including individuals with diabetes in the multilevel group increased from $9.6 \%$ in 2001 to $17.4 \%$ in 2014 (annual increase $0.6 \%, \mathrm{p}<0.01$ ) (table 1B).

Regional variances

Table 2A,B presents the regional variances in percentages of endovascular treatments among the conducted multilevel treatments based on regression analysis. Table 2A shows that the average annual increase across the regions was $2.5 \%(\mathrm{p}<0.01)$, whereas the Northern, South-Eastern and Central performed from $14.1 \%$ to $17.5 \%$ ( $p$ values $<0.01$ ) more multilevel endovascular treatments compared with the Western NRHA during the period. Table 2B shows the differences in annual growth between the regions. The South-Eastern had an estimated average annual growth of $1.9 \%$ during the period, while the Western had a growth of $4.2 \%$ ( $p$ values $<0.01$ ). However, the South-Eastern also started at the highest estimated share, $35.7 \%$ more than the reference group (the Western). This indicates that the growth was highest in regions that started at lower shares.

\section{Aortoiliac revascularisations}

Total numbers

Treatments sessions of 17118 were registered with procedure codes from only the aortoiliac level. In these, $12826(74.9 \%)$ of the patients were aged $\geq 60$ years and $10074(58.9 \%)$ were men. Of the aortoiliac revascularisations, $3783(22.1 \%)$ contained only open procedure codes while 13201 (77.1\%) contained only endovascular codes. Categorised as hybrid treatments were 134 $(0.8 \%)$ (see online supplementary appendix $2 \mathrm{~B}$ ).

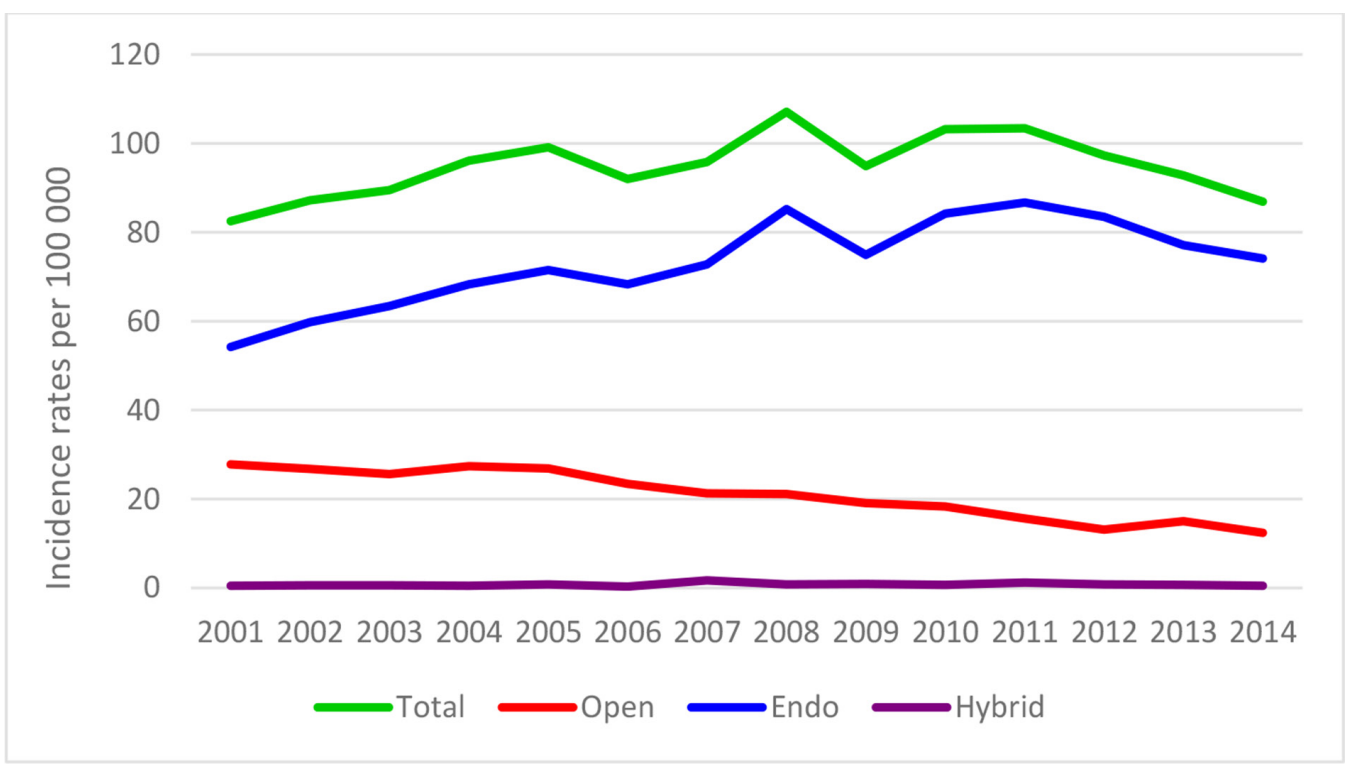

Figure 2 Trends in aortoiliac revascularisations (treatment sessions) in age group $\geq 60$ years. 


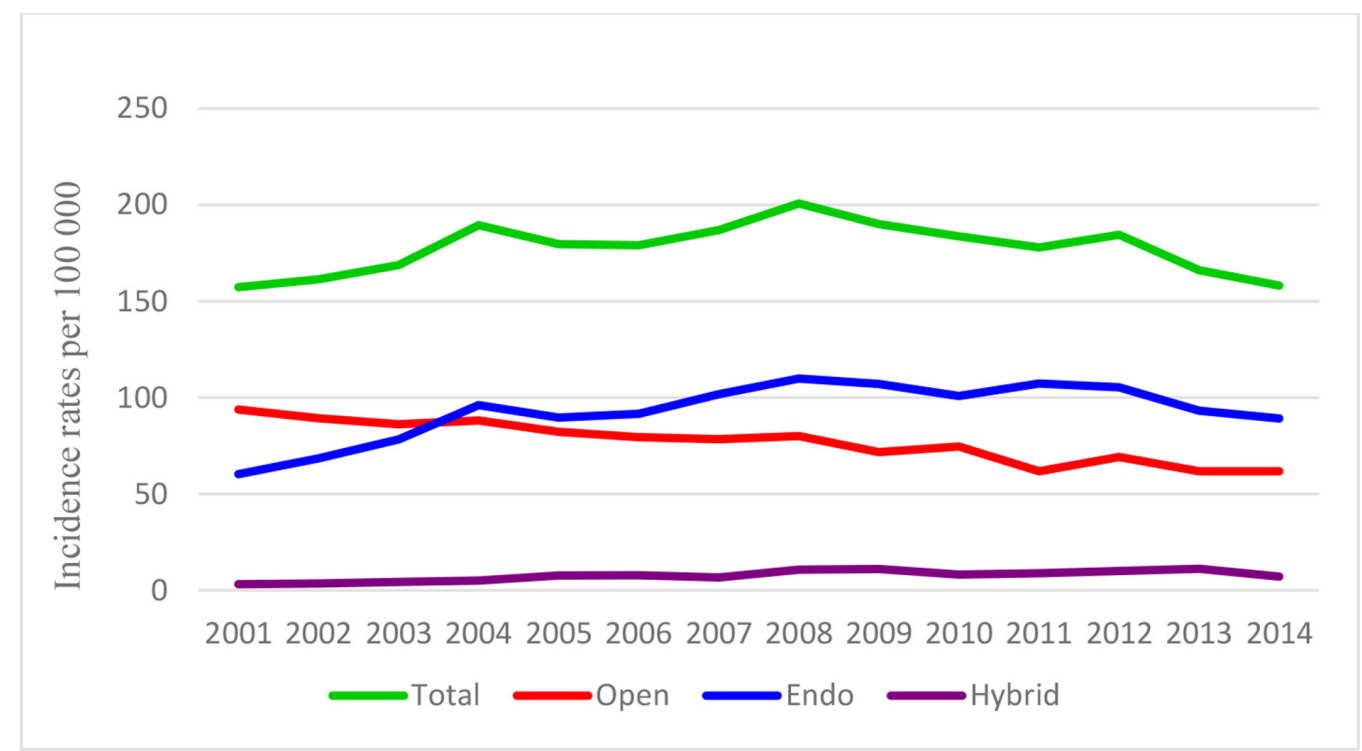

Figure 3 Trends in femoral to popliteal revascularisations (treatment sessions) in age group $\geq 60$ years.

\section{Incidence rates}

The annual incidence rates of open aortoiliac revascularisations decreased from 27.8 to 12.4 per 100000 for the age group $\geq 60$ years (annual change $-1.3 ; \mathrm{p}<0.01$ ). Endovascular revascularisations increased from 54.2 to 74.1 (annual change $1.8 ; \mathrm{p}<0.01$ ) while hybrid revascularisations remained at 0.5 (annual change $0.02 ; \mathrm{p}=0.52$ ) (table 1A).

Developments of treatments in individuals with diabetes

The treatments including individuals with diabetes in the aortoiliac group increased from $8.7 \%$ in 2001 to $15.9 \%$ in 2014 (annual increase $0.4 \%, \mathrm{p}<0.01$ ) (table 1B).

\section{Regional variances}

Table 3A,B presents the regional variances of endovascular treatments among the conducted aortoiliac treatments. Table 3A shows that the average annual increase across the regions was $1.4 \%(\mathrm{p}<0.01)$ whereas the SouthEastern, Central and Western performed from $3.0 \%$ to $6.9 \%$ ( $\mathrm{p}$ values $\leq 0.05$ ) more aortoiliac endovascular treatments compared with the Northern NRHA during the period. Table 3B shows the differences in annual growth between the regions. The Central had an estimated average annual growth of $0.03 \%(\mathrm{p}=0.91)$ while the Northern NRHA, that started at the lowest share, had a growth of $1.8 \%(\mathrm{p}<0.01)$.

\section{Femoral to popliteal revascularisations}

Total numbers

Treatment sessions of 26668 were registered in the femoral to popliteal revascularisation group. In these, $23952(89.8 \%)$ of the patients were aged $\geq 60$ years and $15428(57.9 \%)$ were men. Of the sessions, 11527 $(43.2 \%)$ were registered with only open procedure codes

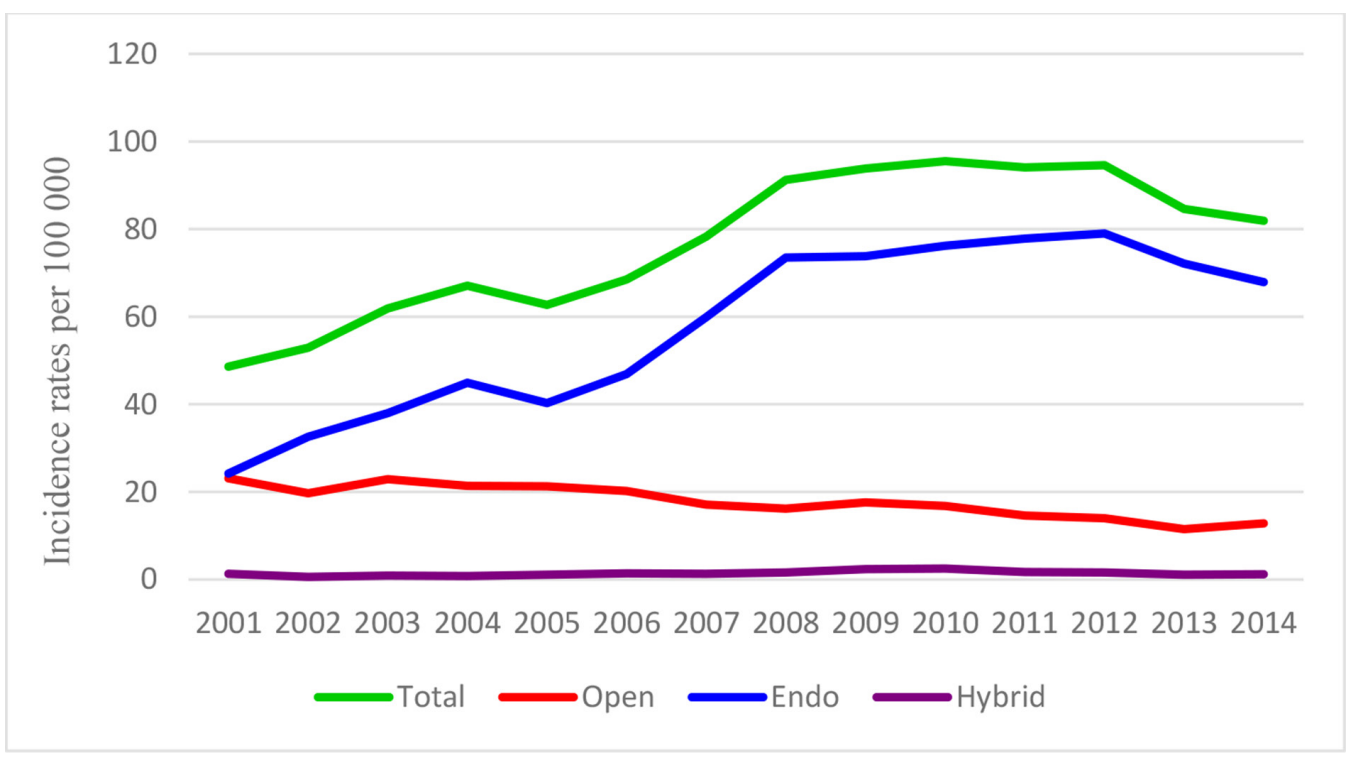

Figure 4 Trends in popliteal to foot revascularisations (treatment sessions) in age group $\geq 60$ years. 


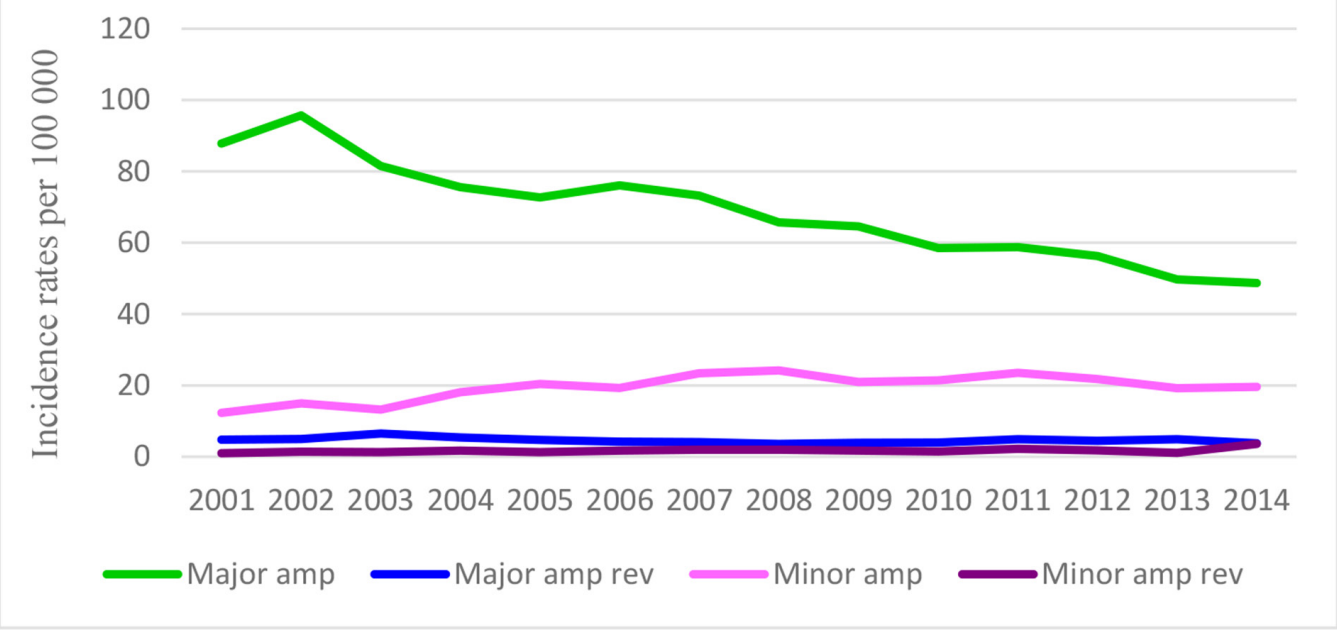

Figure 5 Trends in lower extremity amputations and revisions (treatment sessions) in age group $\geq 60$ years.

and $13980(52.4 \%)$ were registered with only endovascular codes. Categorised as hybrid treatments were 1161 $(4.4 \%)$ (see online supplementary appendix 2C).

\section{Incidence rates}

The annual incidence rates of open femoral to popliteal revascularisations decreased from 93.8 to 61.8 per 100 000 for the age group $\geq 60$ years (annual change -2.5 ; $\mathrm{p}<0.01)$. Endovascular revascularisations increased from 60.3 to 89.2 (annual change $2.2 ; \mathrm{p}=0.01$ ). Hybrid revascularisations increased from 3.2 to 7.2 (annual change 0.5; $\mathrm{p}<0.01$ ) (table 1A).

\section{Developments of treatments in individuals with diabetes}

The treatments including individuals with diabetes in the femoral to popliteal group increased from $13.3 \%$ in 2001 to $22.9 \%$ in 2014 (annual increase $0.7 \%, \mathrm{p}<0.01$ ) (table 1B).

\section{Regional variances}

Table 4A,B presents the regional variances of endovascular treatments among the conducted femoral to popliteal treatments. Table $4 \mathrm{~A}$ shows that the average annual increase across the regions was $1.6 \%(p<0.01)$, whereas the Central, Western and South-Eastern performed from $11.6 \%$ to $19.6 \%$ ( $p$ values $<0.01$ ) more endovascular treatments in this group compared with the Northern NRHA. Table 4B shows the differences in annual growth between the regions. The South-Eastern had an estimated average annual growth of $1.1 \%$ while the Western NRHA that had a lower share in 2001, had a growth of $3.2 \%$ ( $p$ values $<0.01)$.

\section{Popliteal to foot revascularisations}

Total numbers

Treatment sessions of 11564 were registered in the popliteal to foot revascularisation group. In these, $10515(90.9 \%)$ of the patients were aged $\geq 60$ years and
$6880(59.5 \%)$ were men. Of the sessions, 2727 (23.6\%) were registered with only open procedure codes, 8623 $(74.6 \%)$ were registered with only endovascular codes. Categorised as hybrid treatment were 214 (1.9\%) (see online supplementary appendix 2D).

\section{Incidence rates}

The annual incidence rates of open popliteal to foot revascularisations decreased from 23.1 to 12.8 (annual change $-0.9 ; \mathrm{p}<0.01)$. Endovascular revascularisations increased from 24.2 to 67.9 (annual change $4.0 ; \mathrm{p}<0.01$ ). Hybrid revascularisations decreased from 1.3 to 1.2 (annual change $0.06 ; \mathrm{p}=0.13$ ) (table $1 \mathrm{~A})$

Developments of treatments in individuals with diabetes

The treatments including individuals with diabetes in the popliteal to foot group increased from $15.7 \%$ in 2001 to $30.2 \%$ in 2014 (annual increase $0.9 \%, \mathrm{p}<0.01$ ) (table 1B).

\section{Regional variances}

Table 5A,B presents the regional variances of endovascular treatments among the conducted popliteal to foot treatments. Table $5 \mathrm{~A}$ shows that the average annual increase across the regions was $2.4 \%(\mathrm{p}<0.01)$, whereas the Northern performed $4.9 \%(\mathrm{p}=0.23)$, the Central $5.1 \%$ $(\mathrm{p}=0.14)$ and the South-Eastern 10.7\% $(\mathrm{p}<0.01)$ more of these endovascular treatments compared with the Western NRHA. Table 5B shows that the South-Eastern had an estimated average annual growth of $1.8 \%$ while the Western NRHA, that started at the lowest share, had a growth of $4.0 \%$ ( $p$ values $<0.01$ ).

\section{Lower extremity amputations}

Total numbers

Treatment sessions of 13074 were registered with one or more procedure codes from the lower extremity amputation groups. In these, $12162(93.0 \%)$ of the patients were 


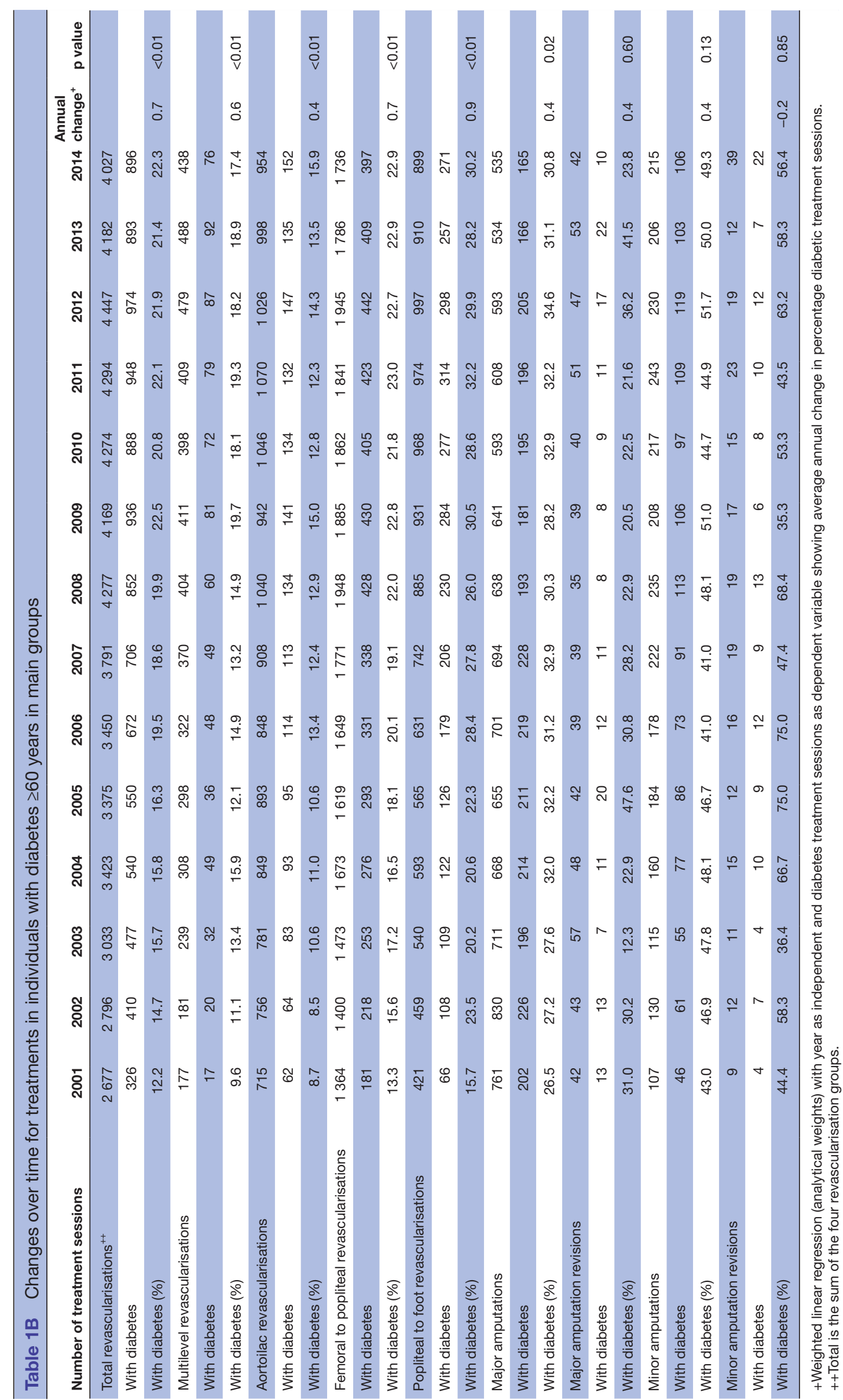


Table 2A Regional overview showing variances in percentages of endovascular treatments among the conducted multilevel revascularisations from 2001 to $2014^{+}$

\section{Percentage \\ multilevel \\ endovascular \\ revascularisations}

\begin{tabular}{lll} 
Region & with $95 \%$ Cl & p value \\
\hline $\begin{array}{l}\text { Average annual national } \\
\text { increase endovascular } \\
\text { revascularisations }\end{array}$ & $2.5(1.9$ to 3.2$)$ & $<0.01$ \\
Western NRHA & Reference group & \\
Central NRHA & $17.5(9.4$ to 25.5$)$ & $<0.01$ \\
South-Eastern NRHA & $16.3(9.6$ to 23.0$)$ & $<0.01$ \\
Northern NRHA & $14.1(5.0$ to 23.2$)$ & $<0.01$
\end{tabular}

Revascularisations=treatment sessions.

Reference group=lowest share.

+Weighted linear regression (analytical weights) with percentage endovascular revascularisations as dependent variable and average annual increases as explanatory variable.

NRHA, Norwegian Regional Health Authority.

aged $\geq 60$ years and $7702(58.9 \%)$ were men (see online supplementary appendix 2E).

\section{Incidence rates}

Treatments categorised as major lower amputations decreased from 87.8 to 48.7 per 100000 for the age group $\geq 60$ years (annual change $-3.2 ; \mathrm{p}<0.01$ ). Major lower amputation revisions decreased from 4.8 to 3.8 (annual change $-0.1 ; \mathrm{p}=0.09$ ). Minor lower amputations increased

Table 2B Regional overview showing average annual increase (\%) in endovascular treatments among the conducted multilevel revascularizations from 2001 to $2014^{+}$

\begin{tabular}{lll}
\hline & $\begin{array}{l}\text { Percentage multilevel } \\
\text { endovascular } \\
\text { revascularisations } \\
\text { with } 95 \% \text { Cl }\end{array}$ & p value \\
\hline Region & $4.2(2.9$ to 5.5$)$ & $<0.01$ \\
\hline Western NRHA *year & $2.7(0.8$ to 4.5$)$ & $<0.01$ \\
Northern NRHA *year & $2.3(0.7$ to 3.8$)$ & $<0.01$ \\
Central NRHA *year & $1.9(1.0$ to 2.7$)$ & $<0.01$ \\
$\begin{array}{lll}\text { South-Eastern NRHA } \\
\text { *year }\end{array}$ & Reference group & \\
Western NRHA (2001) & $35.7(21.0$ to 50.4$)$ & $<0.01$ \\
South-Eastern NRHA & $34.0(14.2$ to 53.8$)$ & $<0.01$ \\
Central NRHA & $26.8(5.8$ to 47.9$)$ & 0.01 \\
\hline Northern NRHA & & \\
\hline
\end{tabular}

Revascularisations=treatment sessions.

Reference group=lowest share.

+Weighted linear regression (analytical weights) with percentage endovascular revascularisations as dependent variable.

*year=average annual change.

NRHA, Norwegian Regional Health Authority.
Table 3A Regional overview showing variances in percentages of endovascular treatments among the conducted aortoiliacal revascularisations from 2001 to 2014

\section{Percentage aortoiliac endovascular revascularisations}

\begin{tabular}{lll} 
Region & with $95 \% \mathbf{C l}$ & p value \\
\hline $\begin{array}{l}\text { Average annual national } \\
\text { increase endovascular } \\
\text { revascularisations }\end{array}$ & $1.4(1.2$ to 1.6$)$ & $<0.01$ \\
Northern NRHA & Reference group & \\
Western NRHA & $6.9(3.6$ to 10.2$)$ & $<0.01$ \\
Central NRHA & $5.8(2.1$ to 9.6$)$ & $<0.01$ \\
South-Eastern NRHA & $3.0(0.1$ to 5.8$)$ & 0.04 \\
\hline
\end{tabular}

Revascularisations=treatment sessions.

Reference group=lowest share.

+Weighted linear regression (analytical weights) with percentage endovascularrevascularisations as dependent variable and average annual increases as explanatory variable.

$\mathrm{NRHA}$, Norwegian Regional Health Authority.

from 12.3 to 19.6 (annual change $0.6 ; \mathrm{p}=0.01$ ), while minor lower revisions increased from 1.0 to 3.6 (annual change $0.1 ; \mathrm{p}=0.04)$ (table $1 \mathrm{~A})$.

Developments of treatments in individuals with diabetes

The treatments including individuals with diabetes in the major lower amputation group increased from $26.5 \%$ in 2001 to $30.8 \%$ in 2014 (annual change $0.4 \%$, $\mathrm{p}=0.02$ ). Major amputation revisions in individuals with diabetes decreased from 31.0 in 2001 to $23.8 \%$ in

Table 3B Regional overview showing average annual increase (\%) in endovascular treatments among the conducted aortoiliac revascularizations from 2001 to $2014^{+}$

\begin{tabular}{llr}
\hline & $\begin{array}{l}\text { Percentage aortoiliac } \\
\text { endovascular } \\
\text { revascularisations } \\
\text { with } 95 \% \text { Cl }\end{array}$ & p value \\
\hline Region & $1.8(1.2$ to 2.3$)$ & $<0.01$ \\
\hline $\begin{array}{l}\text { Sorthern NRHA *year } \\
\text { *year }\end{array}$ & $1.6(1.4$ to 1.9$)$ & $<0.01$ \\
Western NRHA *year & $1.4(1.0$ to 1.7$)$ & $<0.01$ \\
\hline Central NRHA *year & $0.03(-0.5$ to 0.6$)$ & 0.91 \\
\hline Northern NRHA (2001) & Reference group & \\
\hline Central NRHA & $18.8(12.5$ to 25.2$)$ & $<0.01$ \\
Western NRHA & $10.0(4.4$ to 15.6$)$ & $<0.01$ \\
South-Eastern NRHA & $3.8(-1.1$ to 8.7$)$ & 0.12 \\
\hline
\end{tabular}

Revascularisations=treatment sessions.

Reference value=lowest share.

+Weighted linear regression (analytical weights) with percentage endovascular revascularisations as dependent variable and average annual increases as explanatory variable.

*year=average annual change.

NRHA, Norwegian Regional Health Authority. 
Table 4A Regional overview showing variances in percentages of endovascular treatments among the conducted femoral to popliteal revascularisations from 2001 to $2014^{+}$

\begin{tabular}{|c|c|c|}
\hline Region & $\begin{array}{l}\text { Percentage } \\
\text { femoral to popliteal } \\
\text { endovascular } \\
\text { revascularisations } \\
\text { with } 95 \% \mathrm{Cl}\end{array}$ & $p$ value \\
\hline $\begin{array}{l}\text { Average annual national } \\
\text { increase endovascular } \\
\text { revascularisations }\end{array}$ & 1.6 (1.2 to 2.0$)$ & $<0.01$ \\
\hline Northern NRHA & Reference group & \\
\hline South-Eastern NRHA & 19.6 (13.7 to 25.4$)$ & $<0.01$ \\
\hline Western NRHA & 16.0 (9.3 to 22.6) & $<0.01$ \\
\hline Central NRHA & 11.6 (4.7 to 18.6$)$ & $<0.01$ \\
\hline
\end{tabular}

Revascularisations=treatment sessions.

Reference group=lowest share.

+Weighted linear regression (analytical weights) with percentage endovascular revascularisations as dependent variable and average annual increases as explanatory variable.

NRHA, Norwegian Regional Health Authority.

2014 (annual change 0.4, $\mathrm{p}=0.60$ ). Minor amputations in individuals with diabetes increased from $43.0 \%$ to $49.3 \%$ (annual change $0.4, p=0.13$ ), while minor amputation revisions in individuals with diabetes increased from $44.4 \%$ to $56.4 \%$ (annual change $-0.2, \mathrm{p}=0.85$ ) (table 1B).

Table 4B Regional overview showing average annual increase (\%) in endovascular treatments among the conducted femoral to popliteal revascularizations from 2001 to $2014^{+}$

\begin{tabular}{lll}
\hline & $\begin{array}{l}\text { Percentage } \\
\text { femoral to popliteal } \\
\text { endovascular } \\
\text { revascularisations } \\
\text { with 95\% Cl }\end{array}$ & \\
\hline Region & p value \\
\hline Western NRHA *year & $3.2(2.4$ to 4.0$)$ & $<0.01$ \\
\hline Northern NRHA *year & $2.2(0.9$ to 3.4$)$ & $<0.01$ \\
\hline Central NRHA *year & $1.6(0.7$ to 2.5$)$ & $<0.01$ \\
\hline $\begin{array}{l}\text { South-Eastern NRHA } \\
\text { *year }\end{array}$ & $1.1(0.6$ to 1.5$)$ & $<0.01$ \\
\hline Northern NRHA (2001) & Reference group & \\
\hline South-Eastern NRHA & $28.0(17.0$ to 39.0$)$ & $<0.01$ \\
\hline Central NRHA & $15.9(2.7$ to 29.1$)$ & 0.02 \\
Western NRHA & $7.4(-5.1$ to 20.0$)$ & 0.24 \\
\hline
\end{tabular}

Revascularisations=treatment sessions.

Reference group=lowest share.

+Weighted linear regression (analytical weights) with percentage endovascular revascularisations as dependent variable.

*year=average annual change.

NRHA, Norwegian Regional Health Authority.
Table 5A Regional overview showing variances in percentages of endovascular treatments among the conducted popliteal to foot revascularisations from 2001 to $2014^{+}$

\begin{tabular}{llc}
\hline & $\begin{array}{l}\text { Percentage popliteal } \\
\text { to foot endovascular } \\
\text { revascularisations } \\
\text { with 95\% Cl }\end{array}$ & p value \\
\hline $\begin{array}{l}\text { Region } \\
\text { increase endovascular } \\
\text { revascularisations }\end{array}$ & $2.4(1.9$ to 2.9$)$ & $<0.01$ \\
$\begin{array}{l}\text { Western NRHA } \\
\text { South-Eastern NRHA }\end{array}$ & Reference group & \\
\hline $\begin{array}{l}\text { Central NRHA } \\
\text { Northern NRHA }\end{array}$ & $5.1(-1.7$ to 11.8$)$ & 0.14 \\
\hline
\end{tabular}

Revascularisations=treatment sessions.

Reference value=lowest value.

+Weighted linear regression (analytical weights) with percentage endovascular revascularisations as dependent variable and average annual increases as explanatory variable. NRHA, Norwegian Regional Health Authority.

Table 5B Regional overview showing average annual increase (\%) in endovascular treatments among the conducted popliteal to foot revascularizations from 2001 to $2014^{+}$

\begin{tabular}{llr}
\hline & $\begin{array}{l}\text { Percentage popliteal } \\
\text { to foot endovascular } \\
\text { revascularisations }\end{array}$ & \\
Region & with $95 \%$ Cl & p value \\
\hline Western NRHA *year & $4.0(3.0$ to 5.0$)$ & $<0.01$ \\
\hline Northern NRHA *year & $3.7(2.0$ to 5.4$)$ & $<0.01$ \\
\hline Central NRHA *year & $2.1(0.8$ to 3.3$)$ & $<0.01$ \\
\hline South Eastern NRHA *year & $1.8(1.3$ to 2.4$)$ & $<0.01$ \\
\hline Western NRHA (2001) & Reference group & \\
\hline South-Eastern NRHA & $29.0(18.0$ to 40.0$)$ & $<0.01$ \\
\hline Central NRHA & $21.4(6.1$ to 36.8$)$ & $<0.01$ \\
\hline Northern NRHA & $8.0(-10.2$ to 26.1$)$ & 0.38
\end{tabular}

Revascularisations=treatment sessions.

Reference value=lowest value.

+Weighted linear regression (analytical weights) with percentage endovascular revascularisations as dependent variable.

* year=average annual change.

NRHA, Norwegian Regional Health Authority.

\section{Other inclusive results}

The number of units that reported revascularisations to NPR changed during the period. In 2001, we identified 34 hospitals and 4 health trusts, in 2007, 15 hospitals and 7 health trusts and in 2014, 13 hospitals and 7 health trusts. Less than $1 \%$ of the treatment sessions in the study included patients treated at other regions than their own. All four NRHA's took part in this exchange of patients across regional borders. 


\section{DISCUSSION}

In line with international trends, this study demonstrated an increase in the total revascularisation rates from 2001 to 2014 caused by an increase in endovascular and hybrid treatments. Rates of open surgery decreased. These trends were similar in all the vascular groups. The increase was highest in the endovascular popliteal to foot group and in the hybrid multilevel group. The decrease was most evident in the open femoral to popliteal group. Parallel to the increase in endovascular revascularisations, the major amputation and major amputation revision rates decreased. This cross-sectional study cannot establish whether this represents a direct cause and effect, neither was the study designed to evaluate other possible causes. However, from 1974 through 2001 to 2014 the percentage of daily smokers in Norway in the age group 16-74 years has gradually reduced from 52 through $30 \%$ to $14 \%$ among men and from 32 through $31 \%$ to $13 \%$ among women. ${ }^{22}$ It is likely that this decrease in smoking habits, has contributed to the reduction in major amputation rates. On the other hand, the percentage of individuals with diabetes increased significantly in all the revascularisation groups and diabetes itself profoundly increases the risk of amputation. ${ }^{1011}$

In the present study and in alignment with diabetic complications, the percentage of individuals with diabetes was highest in the patient groups with popliteal to foot revascularisations and amputations, in particular minor amputations and minor amputation revisions. Although diabetes occurrence appears to be levelling off in Norway, the prevalence of oral antidiabetic use increased from $2.5 \%$ in 2005 to $3.2 \%$ in 2011 . The use increased strongly with age with a peak in men at age $76(12.4 \%)$ and in women at age $80(9.9 \%) .^{23}$ As the population in Norway is ageing, the number of patients with diabetes with peripheral arterial disease is likely to further increase.

A recent German study highlighted the high rates of limb amputation and mortality in patients with peripheral arterial disease and diabetes, and particularly in those with diabetic foot syndrome in an in-hospital setting. Patients with diabetics also had a high reamputation risk for the ipsilateral and contralateral limb during a longterm follow-up. Possible reasons for this are that patients with diabetes are inadequately and insufficiently diagnosed and treated before an amputation. ${ }^{10}$ A study from Norway and the city of Trondheim showed a $40 \%$ decline in major amputations (amputation through or above the ankle joint) in patients with diabetes from 1996 to 2006 simultaneously as a diabetic foot team started consultation services. These results could not be attributed to an increase in vascular interventions because this rate was unchanged in the same period. In addition to information and preventive care, the main treatment strategy for the diabetic foot team was off-loading of neuropathic ulcers, vascular intervention in cases of neuroischaemic ulcers and radical debridement in cases of chronic osteomyelitis. ${ }^{24}$ To further reduce the national incidence of diabetic amputations, the primary health and specialist health service in Norway must cooperate more closely. ${ }^{25}$ Our study demonstrated a higher percentage of men than women in all age groups. The underlying causes for these results need further population-based investigations.

This study documented regional variances in use of endovascular revascularisations both within and between the vascular groups. It is unlikely that these variations were caused by regional differences in the anatomy of the lesions or basic variations in the occurrence of peripheral arterial disease alone. More likely, these regional variances indicate a difference in availability of endovascular technology. Regional variations in use of endovascular technology in Norway have also been demonstrated for abdominal aortic aneurysms. ${ }^{26}$ The developments in endovascular interventions require resources and new medical equipment, education of staff and new organisation models with cooperation between vascular surgeons and radiologists. Norway's geography, with large and sparsely populated areas, challenges the political goal of equal access to healthcare. In some regions, travel distances to even a small hospital are several hours and it is difficult to staff and equip all treatment sites in a specialised endovascular mode. Since the first report from the Norwegian association for vascular surgery in 2001 about the provision of vascular surgery, there has been an ongoing debate about where vascular treatments should be performed. ${ }^{27} 28$ Centralising versus decentralising, threats to hospital's future existence and the relationship between volume and quality have been thoroughly debated without any conclusive results.

In this study, it was not possible to assess the developments in numbers of treatment cites because the reporting routines varied among the hospitals and health trusts during the period. Although our analysis indicated that the regions with the lowest share had the highest annual growth in endovascular treatments, it is uncertain when and if the regions will be equal in performance of these treatments. We therefore encourage an assessment of professional and technological resources at all present treatment sites for revascularisations and suggest an allocation of future revascularisations to specialised vascular centres in the regions. New technology is introduced in many medical specialities. If the healthcare system is not organised accordingly, regional variances in treatment strategies will become an increasing challenge for several specialities.

This study was based on material from the NPR. All hospitals in Norway must report to this registry directly or through their health trust when they discharge patients. The authorities use the NPR for statistics and to calculate reimbursements through the diagnoses-related group system. Fifty per cent of the hospitals' funding was based on these data in $2014 .^{29}$ Thus, there is also an economic incentive to report. To investigate the quality of data in the study, a selection of numbers registered in the NPR were compared with the corresponding numbers in NorKar, the clinical quality registry for vascular surgery in Norway. This registry was established in 1996 but national 
registration routines have been incomplete. Since 2013, it has been mandatory to report also to NorKar. One hospital from each of the four regions was identified in both registers for 2013. Compared with 1189 aortoiliac and infrainguinal treatment sessions registered in the NPR, 937 (78.8\%) were reported to NorKar. ${ }^{30}$

A central registry for amputations was first established in Norway in 2014. ${ }^{31}$ Thus, to validate the numbers of amputations used in this study, several of the treatment sites were contacted. The local registration routines for amputations varied both within and between these sites. This made a large-scale validation between local registries and the numbers registered in the NPR difficult. Eventually, a hospital in the Western NRHA provided a list with treatment sessions on major amputations and major amputation revisions from 2001 to 2013. Compared with 586 treatment sessions in the local registry, 545 (93.0\%) were registered in the NPR.

\section{Strength and weaknesses in the study}

Our study is the first to show Norwegian trends in open and endovascular revascularisations including lower extremity amputations, the diabetic prevalence in these treatments and regional variances in use of endovascular technology. Large datasets, such as the one used in the present study, are the only valid method available for recognising national trends in patient treatments. However, there are also limitations. Results are subject to potential errors in records, coding and analyses. The treatment sessions were anonymous and some patients were included more than once in the statistics. The study was designed to investigate trends in the numbers of treatments and not indications for treatment, clinical outcomes or causal relations. Planning for future healthcare should also include cost analysis, in addition to outcome measures like short and long-term survival, thus including knowledge of quality and not only trends of practice.

\section{CONCLUSION}

Trends in the numbers of open and endovascular revascularisations and amputations in lower extremities in Norway from 2001 to 2014 were in line with international experience. The increases in treatment sessions involving patients with diabetes underlines the long-term complications associated with diabetes. The population in Norway is ageing and an increase in patients with diabetes and peripheral arterial disease must be expected. The study documented regional variances in the increased use of endovascular treatments, indicating that the availability of this technology differed. To provide equal healthcare to the population, we suggest an allocation of future revascularisations to specialised vascular centres.

\footnotetext{
Author affiliations

${ }^{1}$ Division of Emergencies and Critical Care, The Intervention Centre, 0slo University Hospital, Oslo, Norway

${ }^{2}$ Department of Informatics, Oslo University Hospital, Oslo, Norway
}

${ }^{3}$ Department of Cardiothoracic and Vascular Surgery, Oslo University Hospital, Oslo, Norway

${ }^{4}$ Medical Faculty, Institute of Clinical Medicine, University of Oslo, Oslo, Norway ${ }^{5}$ Institute of Transport Economics, Oslo, Norway

Contributors KW, EF and KKS designed the study. RK conducted the data collection from the Norwegian Patient Register with support from KW. FG conducted the statistical analyses in cooperation with KW. KW wrote the draft of the manuscript. All authors contributed to the interpretation of data, critically reviewed the manuscript and approved the final version.

Disclaimer Data from the Norwegian Patient Registry was used in this publication. The interpretation and reporting of these data are the sole responsibility of the authors. No endorsement by the Norwegian Patient Registry is intended nor should be inferred.

Competing interests None declared.

Provenance and peer review Not commissioned; externally peer reviewed. Data sharing statement No additional data are available.

Open Access This is an Open Access article distributed in accordance with the Creative Commons Attribution Non Commercial (CC BY-NC 4.0) license, which permits others to distribute, remix, adapt, build upon this work non-commercially, and license their derivative works on different terms, provided the original work is properly cited and the use is non-commercial. See: http://creativecommons.org/ licenses/by-nc/4.0/

C) Article author(s) (or their employer(s) unless otherwise stated in the text of the article) 2017. All rights reserved. No commercial use is permitted unless otherwise expressly granted.

\section{REFERENCES}

1. Rowe VL, Lee W, Weaver FA, et al. Patterns of treatment for peripheral arterial disease in the United States: 1996-2005. J Vasc Surg 2009;49:910-7.

2. Goodney PP, Beck AW, Nagle J, et al. National trends in lower extremity bypass surgery, endovascular interventions, and major amputations. J Vasc Surg 2009;50:54-60.

3. Bradbury A, Ruckley C, Fowkes F, et al. Bypass versus angioplasty in severe ischaemia of the leg (BASIL): multicentre, randomised controlled trial. Lancet 2005;366:1925-34.

4. Tendera M, Aboyans V, Bartelink M-L, et al. ESC Guidelines on the diagnosis and treatment of peripheral artery diseases. Eur Heart $J$ 2011;32:2851-906.

5. Fowkes FG, Rudan D, Rudan I, et al. Comparison of global estimates of prevalence and risk factors for peripheral artery disease in 2000 and 2010: a systematic review and analysis. Lancet 2013;382:1329-40.

6. Hirsch AT, Duval S. The global pandemic of peripheral artery disease. Lancet 2013;382:1312-4.

7. Norgren L, Hiatt WR, Dormandy Ja, et al. Inter-society consensus for the management of peripheral arterial disease (TASC II). Eur J VasC Endovasc Surg 2007;33(1):S1-S75.

8. Haltmayer M, Mueller T, Horvath W, et al. Impact of atherosclerotic risk factors on the anatomical distribution of peripheral arterial disease. Int Angiol 2001;20:200.

9. Marso SP, Hiatt WR. Peripheral arterial disease in patients with diabetes. J Am Coll Cardiol 2006;47:921-9.

10. Malyar NM, Freisinger E, Meyborg M, et al. Amputations and mortality in in-hospital treated patients with peripheral artery disease and diabetic foot syndrome. J Diabetes Complications 2016;30:1117-22.

11. Eraso LH, Fukaya E, Mohler ER, et al. Peripheral arterial disease, prevalence and cumulative risk factor profile analysis. Eur $J$ Prev Cardiol 2014;21:704-11.

12. Rooke TW, Hirsch AT, Misra S, et al. ACCF/AHA Focused update of the guideline for the management of patients with peripheral artery disease (updating the 2005 guideline): a Report of the American College of Cardiology Foundation/American Heart Association Task Force on Practice Guidelines Developed in Collaboration With the Society for Cardiovascular Angiography and Interventions, Society of Interventional Radiology, Society for Vascular Medicine, and Society for Vascular Surgery. J Vasc Surg 2011;54:e32-58.

13. Egorova NN, Guillerme S, Gelijns A, et al. An analysis of the outcomes of a decade of experience with lower extremity 
revascularization including limb salvage, lengths of stay, and safety. $J$ Vasc Surg 2010;51:878-85.

14. Malyar N, Fürstenberg T, Wellmann J, et al. Recent trends in morbidity and in-hospital outcomes of in-patients with peripheral arterial disease: a nationwide population-based analysis. Eur Heart $J$ 2013;34:2706-14.

15. Hynes N, Mahendran B, Manning B, et al. The influence of subintimal angioplasty on level of amputation and limb salvage rates in lower limb critical ischaemia: a 15-year experience. Eur J Vasc Endovasc Surg 2005;30:291-9.

16. Bhatt DL, Flather MD, Hacke W, et al. Patients with prior myocardial infarction, stroke, or symptomatic peripheral arterial disease in the CHARISMA trial. J Am Coll Cardiol 2007;49:1982-8.

17. The Norwegian Directorate of Health. Guidelines for the distribution of data from the Norwegian Patient Register, 2009. https:// helsedirektoratet.no/Documents/English/guidelines.pdf (accessed 1 Jan 2017).

18. Nordic Centre for Classifications in Health Care. NOMESCO Classification of Surgical Procedures (NCSP). 16, 2011. version 1. http://www.nordclass.se/NCSP 1_16.pdf

19. Kith H. ICD-10: Den internasjonale statistiske klassifikasjon av sykdommer og beslektede helseproblemer. 10 revision. Oslo: Helsedirektoratet, 2011.

20. Carmona GA, Hoffmeyer P, Herrmann FR, et al. Major lower limb amputations in the elderly observed over ten years: the role of diabetes and peripheral arterial disease. Diabetes Metab 2005;31:449-54.

21. Ephraim PL, Dillingham TR, Sector M, et al. Epidemiology of limb loss and congenital limb deficiency: a review of the literature. Arch Phys Med Rehabil 2003;84:747-61.
22. Statistisk sentralbyrå. Statistics. 2014 www.ssb.no (accessed 3 Mar 2015).

23. Strøm H, Selmer R, Birkeland $\mathrm{Kl}$, et al. No increase in new users of blood glucose-lowering drugs in Norway 2006-2011: a nationwide prescription database study. BMC Public Health 2014;14:520.

24. Witsø E, Lium A, Lydersen S. Lower limb amputations in Trondheim, Norway: A 40\% reduction in diabetic major lowerlimb amputations from 1996 to 2006. Acta orthopaedica 2010;81:737-44.

25. Wits $\varnothing \mathrm{E}$, Lium A, Langeng $\mathrm{E}$, et al. Diabetic foot team and incidence of amputations. Tidsskr Nor Laegeforen 2011;131:804-5.

26. Wendt K, Kristiansen R, Krohg-Sørensen K, et al. Trends in abdominal aortic and iliac aneurysm repairs in Norway from 2001 to 2013. Eur J Vasc Endovasc Surg 2016;51:194-201.

27. Lindahl AK. Commentary to:trends in treatments of abdominal aorticand iliac aneurysm repairs in Norway from 2001 to 2013: mapping of clinical practice: a mirror for clinicians and decision makers. Eur $J$ Vasc Endovasc Surg 2016;51:202.

28. Norsk karkirurgisk forening. Struktur og organisering av Norsk karkirurgi i fremtiden: Den norske legeforening, 2002.

29. Helsedirektoratet. Innsatsstyrt finansiering 2014: Helsedirektoratet, 2013.

30. Altreuther M, Berge C, Halbakken E, et al. NORKAR - Norsk karkirurgisk register - Årsrapport 2013: Seksjon for medisinske kvalitetsregistre, St. Olavs Hospital 2014.

31. Nilsen F, Molund M, Husebye EE, et al. Hallux valgus- og amputasjonskirurgi. Nasjonalt kvalitetsregister i drift. Norsk ortopedipost, nr 1, årgang 19, 2015. 